\title{
The effects of locus of control instructions and reinforcement contingency on performance in a two-choice situation'
}

ROBERT A. BARON, ${ }^{2}$ DEPARTMENT OF PSYCHOLOGY, UNIVERSITY OF IOWA, Iowa City, Iowa 52240

An experiment was conducted to investigate the effects of locus of control instructions and reinforcement contingency on performance in a two-choice situation. Results indicated that Ss made significantly more correct responses under reinforcement for dominant than non-dominant responses, but that contrary to the results of previous experiments, locus of control instructions failed to produce a significant effect upon performance.

The results of several experiments (e.g., Baron, 1967; James \& Rotter, 1958; Watson \& Baumal, 1967) have indicated that locus of control instructions produce significant effects upon performance in various situations. These instructions describe a given situation to Ss as one in which they can (Internal Control) or cannot (External Control) influence their own outcomes. The present experiment was designed to investigate the effects of locus of control instructions on performance under two different reinforcement contingencies, (reinforcement for dominant or non-dominant responses). Specific predictions were:

1. The Ss would make more correct responses under Internal Control instructions than under External Control instructions.

2. The Ss would make more correct responses under the contingency of reinforcement for dominant responses than under the contingency of reinforcement for non-dominant responses.

A simple two-choice situation in which certain responses on the part of Ss are clearly dominant at the start of training was employed to investigate these predictions.

Method

Seventy-two male undergraduates enrolled in sections of introductory psychology at the University of Iowa participated in this experiment. A 3 by 2 factorial design employing 12 Ss in each group was used. The three levels of locus of control instructions were Internal, Neutral, and External Control. The two levels of reinforcement contingency were reinforcement for dominant (RDR) and non-dominant (RNDR) responses. The apparatus consisted of two $35 \mathrm{~mm}$ slides, 50 Unknown Alternative cards (UA cards), Score Sheets, a $15 \mathrm{~W}$ signal light, and a Kodak Carousel slide projector. The slides contained a typed +1 or -1 . The UA cards consisted of $503 \times 5$ in. cards on each of which was typed a number from -2 to -6 or +2 to +6 . The Score Sheets contained $i 00$ numbered spaces in which $S s$ entered their decisions on each trial. The task employed was adapted from previous experiments (e.g., Myers \& Sadler, 1960). The Ss were informed that each time a slide was shown, they would have the opportunity of accepting either the outcome shown on that slide (i.e., win or lose one point) or the outcome indicated on an UA card. They were instructed to indicate their choices by saying "slide" or "card" each time a slide was presented. The Ss kept a record of their decisions on the Score Sheet. If they accepted an UA card they entered a check mark on the Score Sheet, but if they accepted the outcome shown on the slide, they entered a +1 or -1 in the appropriate space on this sheet. They were told that at the end of the series of slides they would be able to go back and turn over one UA card for each check mark they had made, and thus determine their outcomes on trials where they accepted one of these cards. The Ss were informed that each time they made a correct response $E$ would inform them of this by flashing the signal light on the table beside them. A correct response was described to Ss as one which resulted in their winning more points than they would have won by making the opposite decision. Actually, E presented reinforcement to Ss on only $80 \%$ of the trials on which they made correct responses. The Ss in the RDR groups received reinforcement for saying "card" when a -1 was shown or "slide" when a +1 was shown. Previous experiments (e.g., Myers \& Sadler, 1960) have shown that these are the dominant responses in this situation. The Ss in the RNDR groups received reinforcement for making the opposite responses. Locus of control instructions were presented immediately before the first trial. Internal Control instructions suggested that $\mathrm{Ss}$ could control their own outcomes because they made all the decisions in the experimental task. External Control instructions suggested that Ss could not control their own outcomes because they had no knowledge of the values shown on the UA cards. Neutral Control instructions presented material neutral with respect to locus of control which was approximately equal in length to the Internal and External Control instructions.

Results

Figure 1 presents the mean number of correct responses made by $S s$ in the six groups in each of 10 blocks of 10 trials.

Inspection of this figure indicates that Ss made more correct responses under reinforcement for dominant responses than under reinforcement for non-dominant responses. However, there were no marked differences between the groups which were attributable to instructions under either reinforcement contingency. A Type III analysis of variance (Lindquist, 1953) performed on these data indicated that both the Reinforcement Contingency effect $(\mathrm{F}=$ $35.05, \mathrm{df}=1,66, \mathrm{p}<.001)$ and the Trials effect $(\mathrm{F}=28.68, \mathrm{df}=$ $9,594, p<.001$ ) were significant. However, the Instructions effect $(F=0.16, d f=1,66, p>.05)$ was not significant, and there were no other significant effects in the analysis. Thus, locus of control instructions did not produce a significant effect upon performance in the present situation. Because inspection of Fig. 1 indicated that under reinforcement for non-dominant responses Ss in the Internal and Neutral Control instructions groups made more correct responses than $S s$ in the External Control Instructions group in the first four blocks of trials, a Type I analysis of variance was performed on these data. The results of this analysis indicated that only the Trials effect was significant $(F=18.44$, df $=3.99, p$ $<.001)$. The interaction between Instructions and Trials was not significant $(F=0.44$, df $=6,99, p>.05)$. Thus, the three

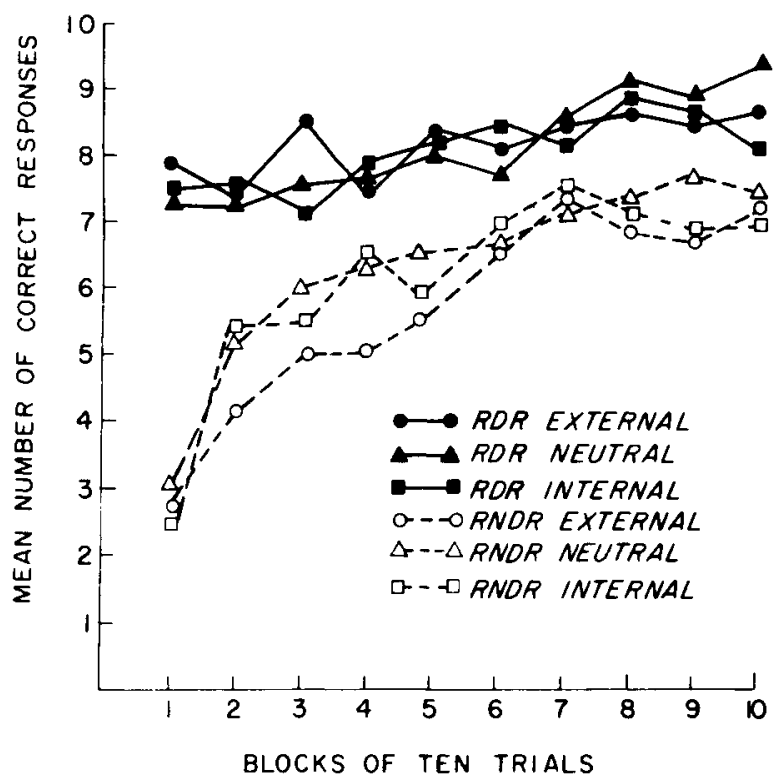

Fig. 1. Mean number of correct responses for each of the six groups as a function of blocks of 10 trials. 
instructions groups did not show significantly different changes in performance over trials.

Discussion

As predicted, Ss made more correct responses under reinforcement for dominant than non-dominant responses. However, locus of control instructions did not have a significant effect upon performance in the present experiment. This latter finding does not agree with the results of a previous experiment (Baron, 1967) which employed the same experimental task as the present study. This experiment found that $S$ s showed significantly superior performance under Internal Control instructions than External Control instructions. In an attempt to improve the design of this experiment, several changes in procedure were introduced in the present study. These changes involved instructions, reinforcing stimuli, and schedules of reinforcement, and may have been responsible for the negative findings of the present experiment. That this was indeed the case is indicated by the fact that a subsequent experiment employing the procedures used by Baron (1967) succeeded in replicating the general pattern of results reported in that study. Thus, the available evidence suggests that any effect of locus of control instructions on performance in the present situation occurs only under fairly specific conditions.

The results of the present experiment indicate that the stimulus employed as reinforcement (i.e., the flash of a light which signified to $S$ s that they made a correct response) was effective in influencing performance. The finding that this stimulus exerted a significant effect upon performance under the contingency of reinforcement for non-dominant responses is of particular interest in this regard, and suggests that being correct in a situation such as the one employed in the present study is a potent reinforcement for human Ss. The results of other experiments have indicated that diverse stimuli such as verbal praise (e.g., Krasner, 1958), successful prediction of an uncertain event (e.g., Kanareff \& Lanzetta, 1960) and the presentation of attitude statements which agree or disagree with Ss' responses to an attitude scale (Byrne, Young, \& Griffit, 1966) may produce similar effects. These results suggest the need for systematic investigation of the stimuli which may serve as reinforcers for human Ss.

\section{REFERENCES}

BARON, R. A. Motivation and performance in skill and chance defined situations. Psychon. Sci, 1967, 9,631-632.

BYRNE, D., YOUNG, R. K., \& GRIFFIT, W. The reinforcement properties of attitude statements. J. exp. Res. Pers, 1966, 1, 266-276.

JAMES, W. H., \& ROTTER, J. B. Partial and $100 \%$ reinforcement under chance and skill conditions. J. exp. Psychol, 1958, 55, 397-403.

KANAREFF, V. T., \& LANZETTA, J. T. The effects of task definition and probability of reinforcement upon the acquisition and extinction of imitative responses. J. exp. Psychol, 1960, 60, 340-348.

KRASNER, L. Studies of the conditioning of verbal behavior. Psychol. Bulh. $1958,55,148-170$.

LINDQUIST, E. F. Design and analysis of experiments in psychology and education. Boston: Houghton Mifflin, 1953.

MYERS, J. L., \& SADLER, E. Effects of range of payoff as a variable in risk-taking. J. exp. Psychol., 1960, 60, 306-309.

WATSON, D., \& BAUMAL, E. Effects of locus of control and expectation of future control upon present performance. J. Pers. soc. Psychol., 1967, 6, 212-215.

\section{NOTES}

1. Based on Experiment Three of a thesis submitted to the Graduate College of the University of Iowa in partial fulfillment of the requirements for the degree of Doctor of Philosophy.

2. Now at the University of South Carolina. 